\title{
Predicting the necessity of LASIK enhancement after cataract surgery in patients with multifocal IOL implantation
}

This article was published in the following Dove Press journal:

Clinical Ophthalmology

7 September 201I

Number of times this article has been viewed

\author{
Pinakin Gunvant ${ }^{1,2}$ \\ Anna Ablamowicz ${ }^{2}$ \\ Subba Gollamudi ${ }^{3}$ \\ 'Western University of Health \\ Sciences, College of Optometry, \\ Pomona, CA, ${ }^{2}$ Southern College \\ of Optometry, Memphis, TN, ${ }^{3}$ Eye \\ Specialty Group, Memphis, TN, USA
}

Correspondence: Pinakin Gunvant Western University of Health Sciences, College of Optometry, 309 E Second Street, Pomona, CA 91766, USA Tel +l 9094698473

Email contact@pinakin-gunvant.com
Purpose: To investigate if the parameters measured routinely prior to cataract surgery with multifocal intraocular lens (IOL) implantation can predict the necessity of additional laser in situ keratomileusis (LASIK) to improve visual outcome.

Methods: Records of patients undergoing cataract surgery between January 2008 and December 2009 were reviewed. Individuals satisfied with visual outcome of cataract surgery and not satisfied were grouped (group 1 and 2, respectively). Preoperative data of refractive error, axial length, corneal astigmatism, intraocular pressure, and postoperative uncorrected visual acuity were recorded. Data was available for 62 patients (104 eyes), of which LASIK enhancement was deemed necessary in 21 eyes (20\%; group 2$)$. The receiver operator characteristic curves were used to discriminate between the groups and linear regression analysis was performed to predict the postoperative visual outcome.

Results: The astigmatism measured preoperatively using manifest refraction had an accuracy of $64 \%$ in discriminating between the groups. Age, spherical component of refraction, axial length, corneal astigmatism, and intraocular pressure were very close to chance prediction $59 \%$, $57 \%, 56 \%, 51 \%$, and $51 \%$, respectively. The postoperative uncorrected visual acuity had an accuracy of $79 \%$ in discriminating the groups. Individuals with uncorrected visual acuity worse than 20/40 after cataract surgery were most likely to undergo LASIK enhancement; however, approximately $20 \%$ of group 2 underwent LASIK enhancement despite having visual acuity of $20 / 30$ or better. When combined, preoperative visual acuity accounted for just $7 \%$ of variance in postoperative uncorrected visual acuity.

Conclusion: Requirement of LASIK enhancement after cataract surgery with multifocal IOL implant is complex in nature, and parameters routinely measured before surgery cannot successfully identify the group requiring LASIK enhancement or predict postoperative uncorrected visual acuity.

Keywords: refractive error, axial length, corneal astigmatism, intraocular pressure, uncorrected visual acuity, visual outcome, multivariate analysis, LASIK enhancement

\section{Introduction}

Cataracts are the leading cause of blindness worldwide, and affect approximately 20.5 million Americans aged 40 years and older. This number is expected to increase by the year 2020 to 30.1 million Americans. Fortunately, blindness due to cataracts is reversible with surgery and most people in developed countries have access to surgery centers. ${ }^{1}$ In the US, the majority of patients use Medicare to help pay for cataract surgery. The estimated government cost of cataract surgery is about US\$3.4 billion per year; this estimate is expected to increase with the heightened prevalence of cataracts in the American population. ${ }^{2}$ 
Multifocal intraocular lenses (IOLs) were first introduced in the late $1980 \mathrm{~s} .{ }^{3}$ With contemporary technological advances in the types of IOLs, cataract and refractive surgeons are now able to correct for both the distance and near refraction, which was not possible even a decade ago. These lenses are of particular interest to individuals who do not wish to wear glasses after cataract surgery. However, these types of "premium lens" implants are not entirely covered under insurance plans or by Medicare, and the extra cost associated with the multifocal IOLs are often borne by the patients. ${ }^{4}$ Despite this, there is increased desire and interest in using multifocal IOLs or other premium lenses after cataract extraction. ${ }^{5}$

Numerous measurements are performed as a part of the evaluation prior to cataract surgery to ensure adequate visual outcome; however, residual refractive error may persist after surgery, which can prevent patients from obtaining satisfactory visual performance. Strategies for correcting this residual refractive error include spectacle correction, contact lenses, enhancement refractive surgery with laser in situ keratomileusis (LASIK) or photorefractive keratectomy, or an IOL exchange. The LASIK enhancement to correct residual refractive error after cataract extraction is shown to be a safe and acceptable procedure. ${ }^{6}$

It would be ideal if there were techniques to predict which patients will require a refractive surgery enhancement after multifocal IOL implantation procedure. This could provide better prognostic knowledge before surgery and improve patient satisfaction postoperatively.

The aim of this study was to evaluate the predictive ability of typical measurements obtained before cataract surgery in determining the necessity of refractive surgery enhancement after cataract surgery.

\section{Methods}

The participants used for this study were patients of a single, fellowship-trained surgeon (SG) at The Eye Specialty Group in Memphis, TN. Patient charts were reviewed, and all individuals having the necessary data evaluated during January 2008 to December 2009 were included in the study. To control for variables induced due to differences in IOLs, only patients with the implantation of multifocal AcrySof ${ }^{\circledR}$ IQ ReSTOR ${ }^{\circledR}$ IOL (Alcon Laboratories, Inc, Fort Worth, TX) were included for analysis. The study was approved by the Institutional Review Board at the Southern College of Optometry.

Before surgery, each patient underwent a comprehensive ophthalmic examination, including refraction and a dilated fundus evaluation. After surgery, each patient returned for a follow-up visit 6 weeks after cataract surgery, where visual acuities were measured using Snellen-equivalent charts. Patients included in the study did not have corneal or retinal pathology. The preoperative data of age, spherical and cylindrical refractive error (subjective refraction), axial length, corneal astigmatism, and intraocular pressure were collected.

The axial length was measured using the IOLMaster $500^{\circledR}$ (Carl Zeiss Meditec Inc, Dublin, CA) and corneal topography was measured using the Pentacam ${ }^{\circledR}$ (Oculus Inc, Lynwood, WA). Intraocular pressure was measured using the Goldmann applanation tonometer. The uncorrected visual acuity values obtained after cataract extraction and IOL implantation were collated and converted to decimal acuities for statistical analysis.

Table 1 provides details of the study participants. The sample size of the study was 104 eyes of 62 patients. Of these, 21 eyes (20\%) had LASIK enhancement following cataract surgery (group 1), whereas 83 eyes $(80 \%)$ did not require additional LASIK enhancement due to visual outcome satisfaction (group 2) as determined by personal interview with each patient.

\section{Statistical analysis}

Chi-square test was performed to evaluate the difference in the number of males and females in the groups. Independent sample $t$-tests were utilized to calculate the difference between the groups. Sensitivity, specificity, and the area under receiver operator characteristic curve (ROC curves) were calculated to evaluate the predictive value of various parameters in distinguishing between the groups. An ROC area of 0.5 or less represents a chance outcome that the parameter was predictive, whereas an ROC area of higher than $0.6,0.7$, or 0.8 was considered to be poor, fair, and good, respectively. Linear univariate and multivariate regression analysis was performed on preoperative parameters to evaluate the predictability of the postoperative visual outcome either using parameters individually or combined. The $R^{2}$ value of regression analysis (amount of variance accounted) was used as a measure of predictability. Because this study involved the use of multiple $t$-tests to evaluate the difference in parameters between the two groups, the $P$ value was adjusted using Bonferroni correction to decrease the chances of type 1 error. A $P$ value of $<0.0062$ was considered to be significant for $t$-tests. A $P$ value of $<0.05$ was considered significant for linear regression analysis.

\section{Results}

Examining for the differences between groups, we found that both the groups had more female patients when compared to male patients; however, the ratio of males versus females was not significantly different between the groups (Chi-square test 
Table I Values of various parameters of study population

\begin{tabular}{|c|c|c|c|c|c|c|c|}
\hline \multirow[t]{3}{*}{ Patient value } & \multirow{2}{*}{\multicolumn{3}{|c|}{$\begin{array}{l}\text { Group I: had LASIK } \\
\text { enhancement surgery } \\
n=2 I \text { eyes (I M/IO F) }\end{array}$}} & \multirow{2}{*}{\multicolumn{3}{|c|}{$\begin{array}{l}\text { Group 2: did not require } \\
\text { LASIK enhancement surgery } \\
n=83 \text { eyes }(10 \mathrm{M} / 40 \mathrm{~F})\end{array}$}} & \multirow{3}{*}{$\begin{array}{l}\text { Independent samples } \\
\text { group I vs group } 2 \\
P \text { value }\end{array}$} \\
\hline & & & & & & & \\
\hline & Mean & SD & Range & Mean & SD & Range & \\
\hline \multicolumn{8}{|l|}{ Preoperative parameters } \\
\hline Age & 63.91 & 6.75 & $50-73$ & 67.02 & 8.62 & $50-88$ & 0.15 \\
\hline Refractive sphere (D) & -0.08 & 2.60 & $-6.50-+3.50$ & 0.60 & 2.65 & $-6.25-+6.50$ & 0.29 \\
\hline Refractive cylinder (D) & -1.30 & 1.26 & $0-4.00$ & -0.60 & 0.61 & $0-2.50$ & 0.0004 \\
\hline Axial length (mm) & 24.02 & 1.46 & $22.47-28.54$ & 23.55 & 1.38 & $20.47-28.12$ & 0.17 \\
\hline Keratometry horizontal & 43.72 & 1.78 & $41.5-46.80$ & 43.75 & 1.90 & $38.88-47.94$ & 0.95 \\
\hline Keratometry vertical & 44.90 & 1.14 & $45.4-43.72$ & 44.25 & 2.00 & $39.99-48.40$ & 0.16 \\
\hline Highest IOP (mmHg) & 18.70 & 3.30 & $14-29$ & 20.00 & 6.40 & $1 \mathrm{I}-44$ & 0.36 \\
\hline VA postoperative uncorrected (logMAR) & 0.45 & 0.17 & $0.10-0.70$ & 0.25 & 0.16 & $-0.02-0.70$ & $<0.0001$ \\
\hline
\end{tabular}

Abbreviations: M, males; F, females; D, diopters; LASIK, laser in situ keratomileusis; SD, standard deviation; IOP, intraocular pressure; VA, visual acuity.

Pearson's $\left.X^{2}=0.73 ; P=0.39\right)$. The amount of astigmatism, as measured by manifest refraction before surgery, was significantly different between groups. The mean astigmatism was greater in group 1 when compared to group 2 (mean difference between groups was -0.69 diopters; independent samples $t$-test $P=0.0004)$. The difference in spherical refraction, axial length, corneal power in vertical and horizontal meridian as measured by Pentacam ${ }^{\circledR}$ (Oculus Inc), highest recorded intraocular pressure, and intraocular pressure recorded prior to surgery were not significantly different between groups (independent samples $t$-test $P>0.15$ in all cases; Table 1).

Table 2 provides sensitivity, specificity, ROC area, and best cut-off value of individual parameters used to differentiate the groups. Using the ROC area as a measure of predictive ability we find that the preoperative parameters were not highly predictive of requirement of LASIK enhancement after cataract surgery with multifocal IOL implant. Of the parameters obtained before surgery, the astigmatic power of the spectacle prescription obtained through manifest refraction was the most predictive and had an accuracy of $64 \%$. Whereas age, spherical component of refraction, axial length, corneal astigmatism, and intraocular pressure were very close to chance prediction and had an accuracy of $59 \%, 57 \%, 56 \%, 51 \%$, and $51 \%$, respectively.
The uncorrected visual acuity obtained after surgery was significantly different between the groups with acuity being better in the group that did not require additional LASIK enhancement (independent samples $t$-test $P<0.0001$ ). The postoperative uncorrected visual acuity accurately predicted in $79 \%$ of the cases the requirement of LASIK enhancement post-cataract surgery. The sensitivity and specificity were $71 \%$ and $76 \%$, respectively with individuals having postoperative acuity of less than 0.48 (approximately 20/40) opting for LASIK enhancement.

Univariate linear regression analysis indicates that all parameters were poorly correlated with postoperative uncorrected visual acuity, with none of the parameters reaching statistical significance (linear regression analysis $P>0.05$; Table 3). Multivariate linear regression analysis shows that combining the effect due to individual parameters does not significantly improve the predictability of the model and only accounts for $7 \%$ variance of the postoperative uncorrected visual acuity data.

\section{Discussion}

Better health care procedures have led to an increase in life expectancy, and individuals with active lifestyles prefer the

Table 2 Parameters predicting the need for laser in situ keratomileusis (LASIK)

\begin{tabular}{llll}
\hline Parameters & Sensitivity & Specificity & ROC area \\
\hline Preoperative data & & & Best cut-off value \\
Refractive sphere (D) & 0.62 & 0.63 & 0.57 \\
Refractive astigmatism (D) & 0.52 & 0.92 & 0.64 \\
Axial length (mm) & 1.00 & 0.19 & 0.56 \\
Corneal astigmatism (D) & 0.38 & 0.83 & $0.5 \mathrm{I}$ \\
Highest IOP (mmHg) & 0.95 & 0.26 & $0.5 \mathrm{I}$ \\
Uncorrected visual acuity (logMAR acuity) & 0.71 & 0.76 & 0.34 \\
\hline
\end{tabular}

Abbreviations: D, diopters; IOP, intraocular pressure; ROC, receiver operator characteristic curve. 
Table 3 Regression analysis between preoperative parameters and postoperative visual acuity

\begin{tabular}{lllll}
\hline Parameters & \multicolumn{2}{l}{ Univariate regression analysis } & & Multivariate regression analysis \\
\cline { 2 - 3 } & $\boldsymbol{R}^{2}$ value & $\boldsymbol{P}$ value & 0.68 & $\boldsymbol{R}^{2}$ value \\
\hline Refractive sphere (D) & 0.00 & 0.07 & 0.32 \\
Refractive astigmatism (D) & 0.03 & 0.07 & \\
Axial length (mm) & 0.01 & 0.45 & \\
Corneal astigmatism (D) & 0.01 & 0.42 & \\
Highest IOP (mmHg) & 0.02 & 0.20 & \\
\hline
\end{tabular}

Notes: $R^{2}$ is the variance accounted, an $R^{2}$ of 1.00 would indicate $100 \%$ variance accounted.

Abbreviations: D, diopters; IOP, intraocular pressure.

comfort, flexibility, and advantages offered by a multifocal IOL when compared to the traditional monofocal IOLs. Medicare, which is the primary bearer of costs of cataract surgery related expenditure, does not cover expenses associated with the choice of multifocal IOL implant. If a premium multifocal IOL is chosen instead of a traditional monofocal IOL, the patient incurs additional expenses that can be significant. ${ }^{7}$ As with any elective procedure, patient expectations are higher when choosing cataract extraction with multifocal IOL implantation compared to traditional monofocal lenses. ${ }^{8}$

Residual refractive error that persists after cataract surgery with IOL implantation is mainly due to variability in parameter measurement during refraction calculation that ascertains the selection of IOL. ${ }^{9} 10$ The healing process of corneal wound is also a variable that may, in part, contribute to the residual refractive error after cataract surgery. An astigmatic type refractive error present prior to surgery has a tendency to persist after surgery and may lead to a residual refractive error as well as decreased visual acuity. ${ }^{11}$ One technique employed to obtain better postoperative visual acuity without the use of spectacles or contact lenses is to perform LASIK enhancement following cataract extraction. This study shows that a postoperative uncorrected visual acuity of worse than 20/40 is the predictive cut-off value in identifying individuals who will require LASIK enhancement procedures following multifocal IOL implantation. Also, patients generally are not satisfied if the postoperative visual acuity is poorer than 20/40 ( $\log$ MAR acuity 0.32$)$; this value is in accordance with the minimum visual acuity require for automobile operation. These findings need to be confirmed using another study that includes an independent dataset.

The results of this study can be helpful in determining the prognosis of visual outcome and establishing management protocols, which may be in better accordance with patient expectations. The present study included only patients who underwent cataract surgery with AcrySof ${ }^{\circledR} \mathrm{IQ}$ ReSTOR ${ }^{\circledR} \mathrm{IOL}$ (Alcon Laboratories, Inc); similar studies are required in the evaluation of other types of specialty IOLs to establish their cut-off values.

Examining the measured preoperative parameters, we found that amount of astigmatism as seen by manifest refraction - and not corneal astigmatism (measured by topography) - was most predictive of the need for LASIK enhancement ( $69 \%$ vs $51 \%$ ). Theoretically, one would expect this outcome considering that manifest refraction accounts for overall astigmatic correction of the eye, whereas astigmatism as provided by corneal topography is predominantly representative of the anterior corneal component. Other parameters, including age, spherical component of refraction, axial length, and intraocular pressure, were not predictive of postoperative LASIK enhancement.

The mean uncorrected visual acuity was poorer in the group that underwent LASIK enhancement (group 1) when compared to the group that did not require LASIK enhancement (group 2). This speaks to the dissatisfaction of visual outcome in patients, and hence the needed additional procedure. However, $20 \%$ of patients in group 1 had a visual acuity better than 20/30 and still chose to undergo LASIK enhancement, suggesting that better visual acuity does not always ensure better visual quality. The quality of vision is a higher-order function and parameters like contrast sensitivity and ocular aberrations, which are not routinely measured, partially could contribute.

One of the limitations of the present study is that a single site and a single surgeon performed all the procedures, and the findings of this study will have to be confirmed by an independent group. It would be ideal if we had good preoperative predictive estimates that identified individuals who would require LASIK enhancement following cataract extraction. To this accord, we found that examining the preoperative parameters routinely measured in clinic are not very predictive of postoperative uncorrected visual acuity, even when evaluating the combined effect of parameters using multivariate analysis. Further research is warranted in this area to identify variables that could better predict postoperative 
visual outcome, effect of surgery on parameters like contrast sensitivity and ocular aberrations, and visual needs related to patient lifestyle.

\section{Acknowledgment}

The authors would like to thank Mr Michael Hoster for his editorial assistance in the preparation of the manuscript.

\section{Disclosure}

The authors report no conflicts of interest in this work.

\section{References}

1. Congdon N, Vingerling JR, Klein BE, et al. Prevalence of cataract and pseudophakia/aphakia among adults in the United States. Arch Ophthalmol. 2004;122(4):487-494.

2. American Academy of Ophthalmology. Eye Health Statistics at a Glance. March 5, 2007. Available from: http://www.aao.org/newsroom/press_kit/ upload/Eye_Stats_3-5-07.pdf. Accessed August 12, 2011.

3. Rabsilber TM, Auffarth GU. Multifocality over the years. March, 2011. Available from: http://bmctoday.net/crstodayeurope/2011/03/article. asp?f=multifocality-over-the-years. Accessed August 12, 2011.
4. Haddrill M. Cataract Surgery Cost. Updated June 23, 2011. Available from: http://www.allaboutvision.com/conditions/cataract-surgery-cost. htm. Accessed August 12, 2011.

5. Bellucci R. Multifocal intraocular lenses. Curr Opin Ophthalmol. 2005;16(1):33-37.

6. Macsai MS, Fontes BM. Refractive enhancement following presbyopiacorrecting intraocular lens implantation. Curr Opin Ophthalmol. 2008;19(1):18-21.

7. Greenbaum S. Cost-benefit analysis of multifocal IOLs versus monovision pseudophakia. J Cataract Refract Surg. 2009;35(4):614.

8. Javitt JC, Wang F, Trentacost DJ, Rowe M, Tarantino N. Outcomes of cataract extraction with multifocal intraocular lens implantation: functional status and quality of life. Ophthalmology. 1997;104(4):589-599.

9. Cochener B, Lafuma A, Khoshnood B, Courouve L, Berdeaux G. Comparison of outcomes with multifocal intraocular lenses: a metaanalysis. Clin Ophthalmol. 2011;5:45-56.

10. Høvding G, Natvik C, Sletteberg O. The refractive error after implantation of a posterior chamber intraocular lens. The accuracy of IOL power calculation in a hospital practice. Acta Ophthalmol (Copenh). 1994;72(5):612-616.

11. Ayala MJ, Pérez-Santonja JJ, Artola A, Claramonte P, Alio JL. Laser in situ keratomileusis to correct residual myopia after cataract surgery. $J$ Refract Surg. 2001;17(1):12-16.
Clinical Ophthalmology

\section{Publish your work in this journal}

Clinical Ophthalmology is an international, peer-reviewed journal covering all subspecialties within ophthalmology. Key topics include: Optometry; Visual science; Pharmacology and drug therapy in eye diseases; Basic Sciences; Primary and Secondary eye care; Patien Safety and Quality of Care Improvements. This journal is indexed on

Submit your manuscript here: http://www.dovepress.com/clinical-ophthalmology-journal

\section{Dovepress}

PubMed Central and CAS, and is the official journal of The Society of Clinical Ophthalmology (SCO). The manuscript management system is completely online and includes a very quick and fair peer-review system, which is all easy to use. Visit http://www.dovepress.com/ testimonials.php to read real quotes from published authors. 